\title{
Spectral Tuning of Chemoreceptor Cells of the Third Maxilliped of the Lobster, Homarus americanus
}

\author{
FRANK COROTTO, RAINER VOIGT, AND JELLE ATEMA \\ Boston University Marine Program, Marine Biological Laboratory, \\ Woods Hole, Massachusetts 02543
}

\begin{abstract}
This is the first investigation of the spectral tuning properties of single chemoreceptor cells of the third maxillipeds (mouthparts) of the lobster Homarus americanus. These organs are used, among other functions, for chemical recognition of food. Based upon extracellular recordings of action potentials, we report on 53 cells identified with a 15-compound equimolar mixture of mostly amino acids in an artificial seawater background (applied mixture concentration $150 \mu M$ ). Subsequently, all cells were tested with each compound separately. Cells were generally narrowly tuned to a single compound. Twentyfive percent of the cells sampled responded best to L-glutamate, $17 \%$ to betaine, $11 \%$ to taurine, and $9 \%$ to ammonium chloride. There was no consistent second best stimulus for these four cell populations. Two other populations were more broadly tuned: one responded best to hydroxy-L-proline and the other to L-arginine. Some cells responded to both compounds. Arginine-sensitive cells (not necessarily "arginine-best" cells) tended to respond also to a lesser degree to leucine. Hydroxy-L-proline-sensitive cells tended to respond to a lesser degree to glycine. Among the lobster's chemoreceptive organs, the tuning of the maxillipeds is the broadest of all and resembles the tuning of the walking legs more than that of the antennules or antennae.
\end{abstract}

\section{Introduction}

The lobster Homarus americanus uses several chemoreceptive appendages to locate, manipulate and ingest food (see for review: Atema, 1985). Lobsters orient toward a distant food odor source using the lateral rami of the biramous antennules (here simply "lateral antennules"), and to a lesser extent the walking legs (Devine and Atema,

Received 9 June 1989; accepted 1 September 1992.
1982). Similar behavioral functions of the antennules have been reported in spiny lobsters (Reeder and Ache, 1980). Near an odor source, lobsters locate food by probing the substrate with the legs until the source is contacted (Derby and Atema, 1982), as do crabs (Schmidt and Gnatzy, 1987). The legs pass the food to the endopodites of the third maxillipeds immediately prior to and during ingestion. Although food quality is probably assessed throughout by all these appendages, they serve different specific functions in the feeding sequence (Derby and Atema, 1982).

Behavioral evidence supports a gustatory, food-evaluating function of the maxilliped. Lobsters require sensory input from maxillipeds to eat; animals with deafferented maxillipeds dropped their food (Derby and Atema, 1982). Maxillipeds are also involved in assessing food palatability. $H$. americanus readily eats filter discs soaked in mussel (Mytilus edulis) extract, but is less eager to accept them if the extract is laced with tannic acid (Derby et al., 1984). Although tannic acid receptors are present in the antennules and legs (and presumably in the mouthparts as well), lobsters began to reject the discs only after holding them in their mouthparts. Similarly, the shrimp Macrobrachium rosenbergii rejects quinine-laced food only after holding it in its mouthparts (Steiner and Harpaz, 1987), and the banana prawn Penaeus merguiensis passes both edible and inedible material to its mouthparts where inedible material is rejected (Hindley, 1975). Although crustaceans appear to use their legs as initial gustatory appendages, they may pay special attention to food being held in their mouthparts which provide a final quality check. A functionally similar arrangement is found in catfish; they use an extraoral sense of taste to locate food odor sources, but the intraoral sense of taste determines palatability (Atema, 1977). 
Single chemoreceptor cells of the lateral antennules (Johnson and Atema, 1983; Weinstein et al., 1990), medial antennular rami ("medial antennules"; Tierney et al., 1988), antennae (Voigt and Atema, 1992), and legs (Johnson et al., 1984) were evaluated with a similar series of compounds selected to probe their spectral tuning. It was found that (1) most receptor cells were surprisingly narrowly tuned, and (2) different appendages contained different blends of cell populations as defined by the single compound to which they were most responsive. The lateral antennules contained prominent populations of cells narrowly tuned to either taurine or hydroxy-L-proline (i.e., "Tau-best" and "Hyp-best" cells); the medial antennules had prominent populations of Hyp-best, Tau-best, and L-arginine-best cells. The antennae were dominated by a Hyp-best cell population. In contrast, leg cell populations were narrowly tuned to either L-glutamate (Glu), betaine (Bet), ammonium chloride $\left(\mathrm{NH}_{4}{ }^{+}\right)$or Hyp. The occurrence of different blends of cell populations in different appendages may be related to different behavioral functions. Physiologically, the chemoreceptive properties of the maxillipeds have not been studied in any detail.

In this study, we evaluated the tuning properties of chemoreceptor cells in the maxilliped to a series of fifteen compounds, including thirteen used in previous studies of other lobster appendages.

\section{Materials and Methods}

Lobsters were obtained from local fishermen and were maintained in unfiltered seawater at the Marine Biological Laboratory in Woods Hole. They were fed squid or fish twice weekly. Experimental methods were adapted from Johnson et al. (1984). The endopodite of the third maxilliped was severed along the merus and placed in a twocompartment preparation chamber where the dactyl and propus were superfused with a stimulus carrier flow of artificial sea water (ASW; flow rate $20 \mathrm{ml} / \mathrm{min}$ ). The dissected sensory nerve was bathed in Homarus Ringer's (Govind and Lang, 1981). The tip of the dactyl was cut off to allow the introduction of a cannula for perfusion with oxygenated Ringer's, which maintained viability for 2-3 h. Action potentials were monitored extracellularly from afferent axons with a suction electrode. Responses were recorded on magnetic tape for later analysis.

Chemoreceptor cells were initially identified by their response to $50 \mu$ l of an equimolar search mixture (Mix) of 15 single compounds (Table I, note abbreviations) each at a final peak concentration of $10 \mu M$ (i.e., total Mix concentration of $150 \mu M$ ) injected into the ASW carrier flow. An equimolar mixture is equally effective as a search stimulus as is a naturally proportioned mixture (Weinstein et al., 1990) and-despite the common effects of "mixture suppression" (see Discussion)—-the most efficient method
Table I

Test stimuli

\begin{tabular}{|c|c|}
\hline Compounds & Abbreviations \\
\hline L-Aspartate & Asp \\
\hline L-Glutamate & Glu \\
\hline Ammonium chloride & $\mathrm{NH}_{4}^{+}$ \\
\hline L-Proline & Pro \\
\hline Sucrose & Suc \\
\hline L-Lysine & Lys \\
\hline L-Glutamine & Gln \\
\hline Betaine & Bet \\
\hline L-Arginine & Arg \\
\hline Hydroxy-L-Proline & Hyp \\
\hline Ethanol & $\mathrm{EtOH}$ \\
\hline L-Alanine & Ala \\
\hline Glycine & Gly \\
\hline Taurine & Tau \\
\hline L-Leucine & Leu \\
\hline $\begin{array}{l}\text { Search mixture-an equimolar mixture of the above } \\
\text { compounds }\end{array}$ & Mix \\
\hline
\end{tabular}

of finding cells responsive to the individual components of the mixture.

Once identified, responsive cells were tested with each of the fifteen single compounds (injected as $50 \mu \mathrm{l}$ volumes), again with a final peak concentration of $10 \mu M$. For Glu-sensitive cells, $10 \mu M$ is at the middle of the mean concentration-response function (see Fig. 3) and well above the thresholds of most of these cells. By measuring conductivity within the stimulation chamber after injecting a $50 \mu \mathrm{l}$ pulse of $1 \mathrm{M} \mathrm{NaCl}$ into a flow of deionized water, we found that stimuli passed over the maxilliped as a pulse of one second duration at half peak height. ASW contained very low concentrations of some of the compounds tested, but rather high $\mathrm{NH}_{4}{ }^{+}$levels (e.g., $\left[\mathrm{NH}_{4}{ }^{+}\right]-1-2 \mu M,[$ Asp $]=5 \mathrm{n} M$, [Gly] $=26 \mathrm{n} M$; HPLC measurements courtesy of Dr. Donal Manahan, University of Southern California).

Stimuli were injected at one minute intervals, during which the stimulation chamber and stimulus introduction port were vigorously flushed with ASW. Stimuli were injected in the order shown in Table I, with every sixth stimulus being Mix as a test for viability. This order was chosen to represent a haphazard (random) sequence of strong and weak stimuli, as determined from previous experiments of chemoreceptor cells in the lateral antennules and walking legs. Responses to the four Mix stimuli showed no systematic decline in magnitude. Thus we infer that preparation viability was maintained throughout the experiments, and that order-bias was not significant. One cell was rejected because its sensitivity to Mix decreased by $60 \%$ over the course of the experiment. A few other cells showed response variability to Mix of greater than $60 \%$ throughout the experiment, however, because there 
was no trend to lower or higher responses, but rather a variability around some fairly constant mean response, these cells were included.

To assess our choice of test concentration, concentration-response functions were determined for $10 \mathrm{Glu}$-sensitive cells; the spectral properties of these cells were not investigated. The cells were identified by their response to a $10 \mu M$ pulse of Glu. Five minutes were allowed to disadapt the cell from the repeated exposures to Glu inherent in searching for a single unit. Then, cells were probed with ascending concentrations of Glu in log steps, from $10^{-11} M$ to $10^{-3} M$.

Single cell responses were identified visually from an oscilloscope trace on the basis of amplitude [with the assistance of a window-discriminator (Frederick Haer \& Co., New Brunswick, ME)], waveform, and latency. Because different cells responded with different temporal patterns, response magnitude was assessed as the total number of spikes. Response durations were less than $5 \mathrm{~s}$. Only six cells were spontaneously active at a low frequency (about $0.1 \mathrm{~Hz}$ ), while others fired occasional bursts of spikes. The responses of the six cells that fired spontaneously at a constant frequency were corrected by subtracting, from the response frequency, the mean spontaneous spike frequency prior to stimulation, as in Johnson et al. (1984). Cells that fired in spontaneous bursts were not recorded because the resulting data could not be interpreted. We present only cells for which complete tuning spectra were determined.

The tuning breadth of cells was described by the $\mathrm{H}$ metric (Smith and Travers, 1979), a measure of diversity:

$$
H=-\mathrm{K} \sum P_{\mathrm{i}} \log _{10} P_{\mathrm{i}},
$$

where $H$ is a measure of response diversity, $K$ is a scaling constant (a function of the number of compounds tested), and $P_{\mathrm{i}}$ is the proportional response of each of the 15 test compounds. The metric is scaled from 0 to 1 , where $H$ $=0$ designates a cell responding to only one stimulus, and $H=1$, a cell responding equally to all stimuli. The tuning breadth of cells was computed without responses to Mix or ASW.

Cells were classified by their best response to a single compound. Cells that responded best to Mix are occasionally termed "Mix-best" cells, although they are classified by their best single compound stimulus. A bestcompound classification for receptor cells does not by itself imply a well-defined cell population.

\section{Results}

The results are based on the responses from 53 cells. Overall, the greatest response-in terms of the total number of spikes generated in all cells-was elicited by Mix, followed by Glu, Tau, Bet, Arg, Hyp, Leu, $\mathrm{NH}_{4}{ }^{+}$and Gly; the remaining seven compounds and ASW were poor stimuli (Table I).

Nineteen cells (36\%) responded best to Mix (Fig. 1) including two cells (\#46; \#49) that responded best to both Mix and to one single compound. The remaining 34 cells responded best to one or another single compound. The 19 Mix-best cells were widely distributed among the cell populations as defined by their best single compound. They included 1 of the 13 Glu cells (\#1-\#13), 1 of 6 Tau (\#14-\#19), 2 of 8 Bet (\#20-\#27), 3 of $5 \mathrm{NH}_{4}{ }^{+}$(\#28-\#32), 4 of 6 Arg (\#33-\#38), 3 of 9 Hyp (\#40-\#48), and 2 of 3 Gly cells (\#49-\#51). Of the three remaining Mix-best cells, one (\#53) responded to none of the single compounds (Figs. 1, 2); the other two responded best to Leu (\#39) and Lys (\#52) respectively. Two of the cells classified here as Arg-best responded equally well to Hyp (\#34) or Leu (\#38), one of the Hyp-best cells responded equally to Gly (\#44), and one Gly-best cell responded equally to Hyp and Bet (\#51; Fig. 2). The latter were all low responses of only a few spikes. Thus, the classification of these latter cells is obviously arbitrary.

The most stimulatory single compound was Glu, which elicited a total of 341 spikes from 17 cells; 13 of these responded better to Glu than to the other single compounds. Eight compounds (Glu, Tau, Bet, Arg, Hyp, Leu, $\mathrm{NH}_{4}{ }^{+}$and Gly) accounted for $89 \%$ of all the spikes generated by single compound stimuli in all cells of this study.

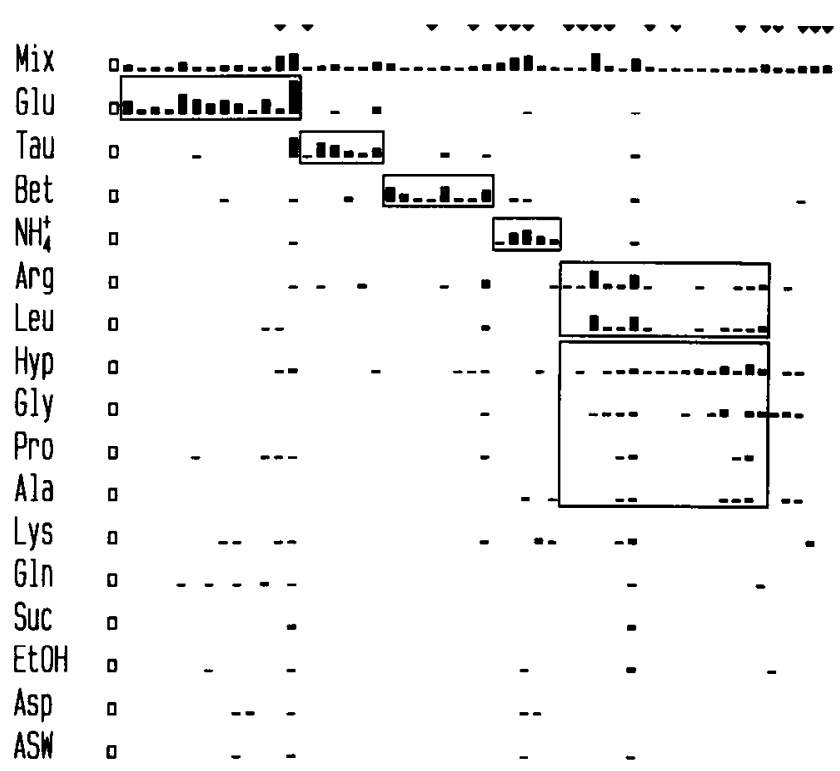

Figure 1. Responses of 53 chemoreceptor cells of the lobster maxilliped. Each column represents the responses (total number of spikes) of a cell to the stimuli on the left. Cells are grouped in best-compound populations, starting with the single compound (Glu) that caused the largest total number of spikes. Open scale bars on far left represent 25 spikes. Arrowheads indicate cells in which the mixture caused an equal or stronger response than their best compound. Boxes reflect response correlations; see text. 
Lys, Pro, Ala, Gin, Suc, EtOH and Asp were relatively ineffective stimuli, each compound eliciting less than 40 spikes in all cells; few cells responded best to these stimuli. These 7 compounds and ASW accounted for the remaining $11 \%$ of all spikes. ASW stimuli caused 7 spikes in 4 cells.

Fourteen of the 53 cells (28\%) responded to only one of the 15 single compounds (Fig. 2). Thirteen cells responded to only two, eight cells to three, and seven cells to four compounds. The remaining ten cells were more broadly tuned. Four of these 10 cells also responded to ASW, including two cells, \#13; \#38, (Fig. 2) that responded to almost all compounds. This response was probably not caused by a contamination of ASW because carrier flow and ASW stimulus were identical. Perhaps these $\Lambda$ SWresponsive cells are both chemo- and mechanoreceptive (Hatt, 1986). Tuning breadth varied across the major cell populations (Table II). As a population, Glu, Tau and Bet cells were most narrowly tuned.

Cells grouped by their best single compound (Figs. 1, 2) formed populations within which the responses to all single compounds tended to be correlated with one another $(P<0.01$, Pearson's Product moment correlation coefficient). These results were similar to the correlation values for responses of lobster walking leg receptor cells (Johnson et al., 1984; data not shown). Within the Glu, Tau, Bet and $\mathrm{NH}_{4}{ }^{+}$cell populations, no single compound was a consistent second best stimulus for the population.

Responses to six compounds-Arg, Leu, Hyp, Gly, Pro, and Ala-appeared correlated, particularly Arg with Leu and Hyp with Gly (Figs. 1, 2). Eleven of the 18 cells that
Table II

Response breadth of major chemoreceptor cell populations based on responses to 15 single compounds

\begin{tabular}{lccrr}
\hline \hline Population & Median $\mathbf{H}$ & Mean $\mathbf{H}$ & Range & N \\
\hline Glu & 0.11 & 0.16 & $0-0.50$ & 13 \\
Tau & 0.19 & 0.17 & $0-0.32$ & 6 \\
Bet & 0.14 & 0.19 & $0-0.59$ & 8 \\
$\mathrm{NH}_{4}{ }^{+}$ & 0.38 & 0.27 & $0-0.57$ & 5 \\
Hyp & 0.25 & 0.31 & $0-0.55$ & 5 \\
Arg & 0.37 & 0.42 & $0-0.82$ & 6 \\
Gly & 0.44 & 0.37 & $0.17-0.50$ & 3 \\
\hline
\end{tabular}

responded to $\Lambda \mathrm{rg}$ also responded to Leu, usually to a lesser degree. Four of the six Arg-best cells (Fig. 2) had strong Leu responses. Similarly, eleven of the 23 cells that responded to Hyp (but were not necessarily Hyp-best cells) responded also, and usually to a lesser degree, to Gly. Five of the nine Hyp-best cells had strong Gly responses. Interstimulus Pearson product-moment correlations showed that responses to Arg were correlated with responses to Leu ( $r=0.99)$, and Hyp with Gly $(r=0.77)$. Pro and Ala responses were correlated, and both were correlated with Hyp and Gly responses.

Individual concentration-response functions for nine Glu-sensitive cells possessed unique characteristics (Fig. 3 ). At the highest three stimulus concentrations, one outlier cell (not shown) fired at rates 3-5 times the mean. Thresholds ranged from $10^{-8} M$ to $10^{5} M$. Some cells saturated at $10^{-5} M$, others did not saturate at the highest

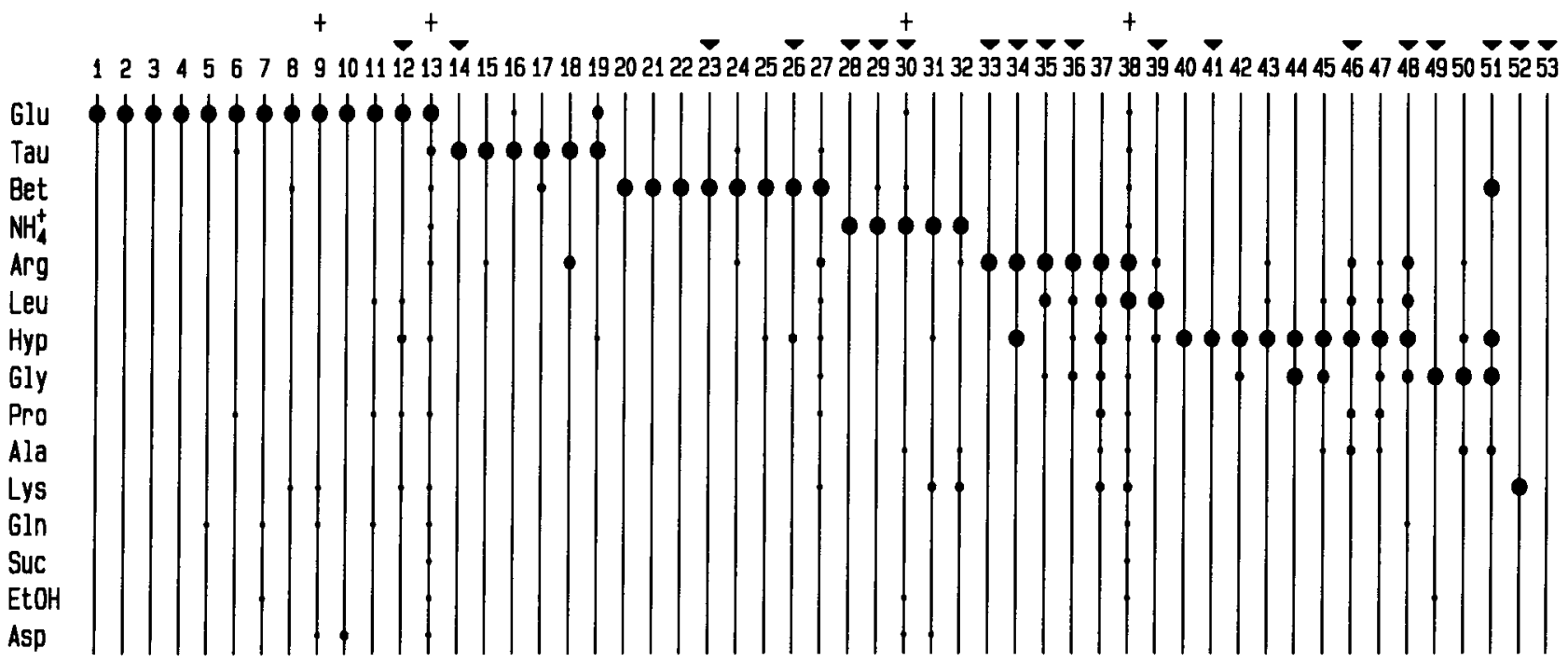

Figure 2. Spectral tuning shown as responses of all cells to all single compounds normalized to the best response (largest dot) of each cell. Decreasing dot sizes represent responses of 70-99\%, 30-69\%, and less than $30 \%$ of that cell's maximum response. Arrowheads indicate cells in which the mixture caused an equal or stronger response than their best compound. Crosses indicate cells responding to ASW. 


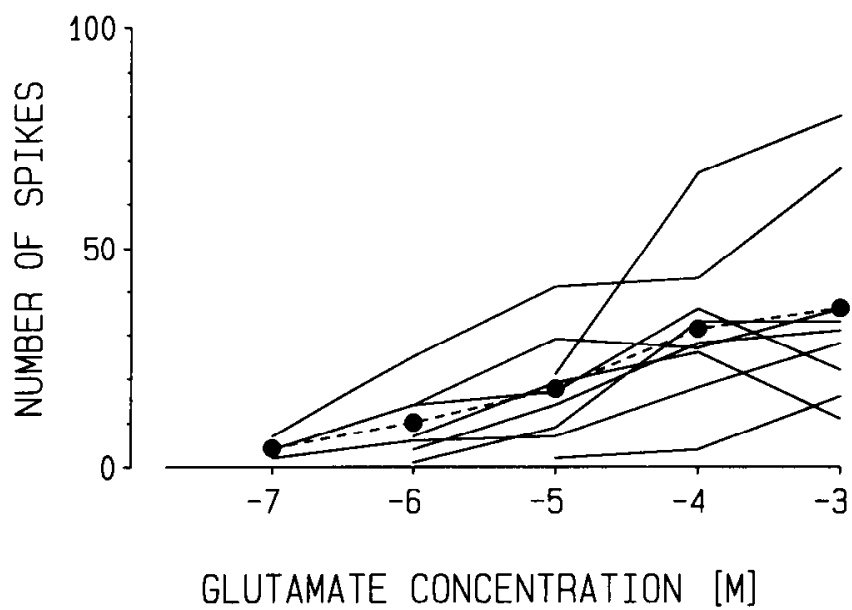

Figure 3. Glu-response functions of nine glutamate-sensitive cells. Five cells responded with one single spike to $10^{-8} \mathrm{M}$ Glu (data not shown). There were no responses to Glu concentrations less than $10^{-8} M$. Mean response function is broken line.

test concentration $\left(10^{-3} M\right)$. Three cells showed greatly reduced responses at the highest test concentration. The mean response function (not including the outlier cell) increased rather linearly from $10^{-7}$ to $10^{-4} \mathrm{M}$, and then saturated.

In 19 cells, the mixture elicited an equal or stronger response than any single compound tested (Fig. 1). Sixteen of these cells had low firing rates, responding with less than 15 spikes to their best compound. Thus, they were rare among generally strongly responding Glu- and Taucells and common among generally weakly responding Arg, $\mathrm{Hyp}, \mathrm{NH}_{4}{ }^{+}$and Gly-cells (Fig. 1). Taking as a criterion a response difference of two spikes (representing about $15 \%$, determined as response variability; Merrill, 1992), nine cells responded more strongly to the mixture than to their best single compound. In six of these cells, the response to the mixture was more than $15 \%$ stronger than the sum of the responses to all single compounds. In four of these cells, the response to the mixture was twice as strong as the sum of the responses to single compounds (Fig. 4).

In 37 cells (Fig. 4), the response to the mixture was $15 \%$ smaller than the sum of the responses to the single compounds. In 32 of these cells, the sum was twice as strong as the response to the mixture.

\section{Discussion}

This study shows that the tuning spectra of chemoreceptor cell populations (defined by best compound) of the third maxillipeds of the lobster $H$. americanus are similar to the tuning spectra of prominent cell populations found in other lobster chemoreceptor appendages. The most remarkable difference with respect to its other appendages is that no single best cell population dominated the maxillipeds (Fig. 2). The maxillipeds are characterized by mostly narrowly tuned Glu- (24.5\%), Tau- (11.3\%), Bet(17.0\%), $\mathrm{NH}_{4}{ }^{+}-(9.4 \%)$, Arg- (11.3\%), and Hyp-best cell populations (17.0\%), with one or two cells responding best to Leu, Lys, or Gly. Overall, the response spectrum of the maxilliped resembles that of the walking legs, but the latter is more strongly dominated by Glu-best cells (37.9\%), in addition to $\mathrm{NH}_{4}{ }^{+}(15.2 \%)$, Hyp- (16.7\%), and Bet-best cell populations (10.6\%), and some Lys-, Tau-, Leu-, and Asp-best cells (Johnson et al., 1984). In contrast to these thoracic appendages, the cephalic appendages are Hypcell dominated. The lateral antennules contain many cells narrowly tuned to Hyp (47.3\%), Tau (15.3\%), and Glu (10.2\%) (Johnson and Atema, 1983; Weinstein et al., 1990). The medial antennules contain large populations of Hyp- (26.4\%), Tau- (24.5\%), and Arg-best cells (20.8\%) and a few Bet- and $\mathrm{NH}_{4}{ }^{+}$-best cells (Tierney et al., 1988). The second antenna was dominated by a Hyp-best cell population $(85.1 \%)$ with small Tau- $(10.6 \%)$ and Bet-cell populations (4.3\%) (Voigt and Atema, 1992). For a further discussion of organ tuning see Voigt and Atema (1992).

Tuning breadth is generally dependent on stimulus intensity; chemoreceptor cells become more broadly tuned at higher stimulus intensities (Ogawa et al., 1974; Voigt and Atema, 1992). Our test concentration of $10 \mu M$ was well above threshold for most of the Glu-sensitive cells tested (Fig. 3). Even at this stimulus intensity, four of the cell populations (Glu, Tau, Bet, $\mathrm{NH}_{4}{ }^{+}$) were narrowly tuned (Table II). Yet, more broadly tuned cells were not uncommon, i.e., Arg and Hyp cell populations.

The Arg-best cells often responded second best to Leu. In fact, Arg and Leu were so highly correlated $(r=0.97)$ that one might suspect that they bind to the same receptor site, despite the different net charges they carry at the $\mathrm{pH}$

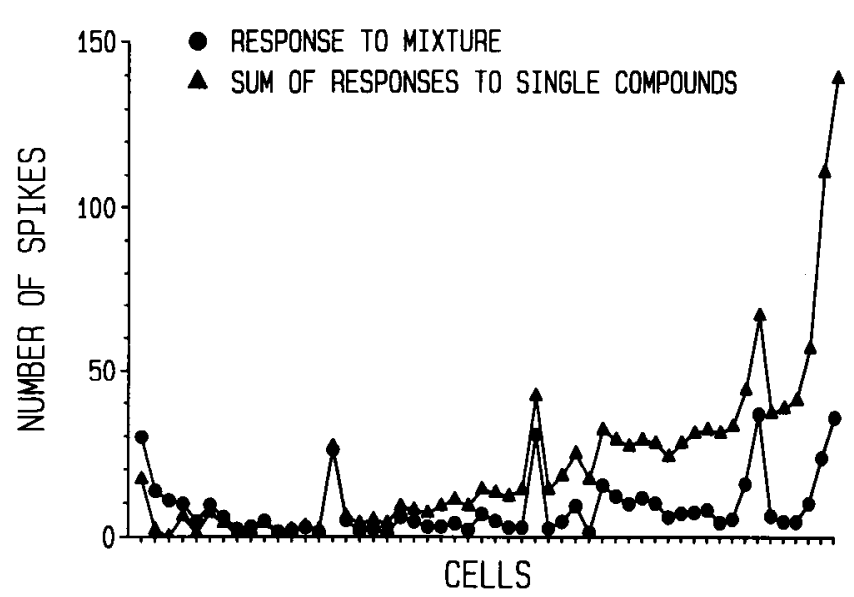

Figure 4. Responses of all 53 cells to the mixture (circle) and to the sum of their responses to 15 single compounds (triangle), ordered by the magnitude of the response difference. 
of ASW. However, Arg and Leu are not as tightly coupled in receptor cells identified in other chemoreceptor organs and Leu is not always second best; Leu-best cells, including cell \#39 in this study (Fig. 2), are not uncommon in the lobster. This would argue for the general independence of separate Arg and Leu receptor sites. The close Arg-Leu response correlation in certain cells would then be based on a specific ratio of simultaneously expressed Arg and I eu binding receptors. In other cells and organs this ratio would be different and variable. This idea appears to have general appeal (Atema et al., 1989; Buck and Axel, 1991; Dionne, 1992). Similar arguments can be made for Hyp and Gly coupling which appears significant $(r=0.77)$ in this study but is not a general rule for lobster receptor cells. The determinant of the particular blends of receptor expression in chemoreceptor cells is now one of the most intriguing unsolved issues in chemosensory research.

Some maxilliped receptor cells showed enhanced responses, and other cells reduced responses to mixture stimuli, whether compared to the response to their best compound or to the sum of responses to all individual mixture components (Fig. 4). This has also been seen in other chemoreceptor organs studied (e.g., Atema et al., 1989; Voigt and Atema, 1992). A common way of expressing mixture suppression (or mixture enhancement) is to compare the observed response to the mixture with an expected response calculated as the sum of responses to individual mixture components, with or without adjustments for the slope of the individual concentrationresponse functions (Caprio et al., 1989; Daniel and Derby, 1987). Since we did not determine concentration-response functions, we have assumed, conservatively, that mixture responses more than $50 \%$ greater or smaller than the sum of the responses to the mixture components reflect enhancement and suppression, respectively. By this criterion we have identified four cells showing mixture enhancement, and 32 cells showing mixture suppression. It is likely that such robust phenomena would be seen under any number of different model assumptions for mixture enhancement and suppression.

We also found 19 cells (38\%) that responded equally or more strongly to the mixture (Figs. 1, 4). Similar Mixbest cells were found in $H$. americunus legs (Gerardo et al., 1989). In comparison with data from cephalic appendages, this is a surprisingly large percentage of cells. In the medial antennule, $96 \%$ of the cells surveyed gave smaller responses to the mixture than to the sum of responses to individual compounds, whereas only $4 \%$ showed enhanced responses (Tierney et al., 1988). Enhanced responses to the mixture were seen before to be characteristic of weakly responding cells (Atema et al., 1989). This was confirmed here: while most other cells were tested well above their thresholds, as shown by the response magnitude for their best compound, most of the
Mix-best cells responded with less than ten spikes to their best single compound (Fig. 4). This suggests that the Mixbest cells were tested close to their threshold. Moderatcly stimulatory compounds might have been subthreshold stimuli when presented alone, thus appearing to be ineffective (Figs. 1, 2). However, when presented as part of Mix, responses to several individual compounds may have been summed, leading to a stronger response to the mixture than to the best single compound or the sum of all responses to the individual components. Therefore, the high percentage of Mix-best cells found in this study may be the result of relatively low stimulus concentrations used here.

The stimulus-response function of Glu cells (Fig. 3) is similar to results obtained from leg chemoreceptors (Derby and Atema, 1982; Johnson et al., 1984, 1985). A $10^{-7} M$ threshold may reflect the ambient concentration of Glu in coastal seawater $\left(2 \times 10^{-8} \mathrm{M}\right.$; Mopper and Lindroth, 1982). The one very highly responsive cell (216 spikes to a brief stimulus pulse of $10^{-4} \mathrm{M}$ Glu) is an anomaly thus far.

As interesting as the physiological and genetic basis for tuning diversity among receptor cells, is the behavioral function of this diversity. Why are so many cclls narrowly tuned? Why are cephalic receptor organs tuned to Hyp and Tau whereas thoracic appendages are tuned to Glu, Bet or $\mathrm{NH}_{4}{ }^{+}$? We may understand the extreme narrow tuning of many insect pheromone receptor cells as an evolutionary response to sexual selection and communication that may have sharpened the tuning specificity of signal and receptor. But narrow tuning in chemoreceptor cells involved in feeding is unusual, and its function not immediately obvious (Johnson et al., 1984; Derby and Atema, 1988). Narrow tuning might improve the detection of key compounds in a (food) mixture odor against ambient chemical (noise) backgrounds. Thus it could enhance chemical orientation in odor plumes via such compounds as Hyp or Tau, which occur in very low background concentrations in natural seawater (Mopper and Lindroth, 1982) and are good indicators of released body fluids (see discussion in Johnson and Atema, 1986). This may suggest an explanation for the presence of many Tau and $H y p$ cells in the antennules and antennae. The case for narrow tuning of Glu, Bet, and $\mathrm{NH}_{4}{ }^{+}$-best cells of the walking legs and maxillipeds is more difficult to make.

It may be easier to explain the blend of differently tuned cell populations in different organs than it is to suggest a strong argument for narrow tuning of individual receptor cells. If Hyp and Tau have good qualities as distance signals, then both narrow cell tuning and the dominance of their cell populations in antennules may be understood. In contrast, legs are used to both locate (Devine and Atema, 1982; Moore et al., 1991) and to evaluate food (Derby and Atema, 1982), and they require rather precise 
and complex blends of amino acids before full behavioral responses can be elicited (Borroni et al., 1986). Their discrimination function may require a more equally distributed blend of cell populations. Maxillipeds do not serve any function in orientation or localization, but play a critical role in evaluating food (Derby and Atema, 1982; Derby et al., 1984). This pure evaluation function may be reflected in the nearly equal distribution of tuning populations reported in this study.

\section{Acknowledgments}

This paper is part of F. C.'s Masters Degree Thesis at the Boston University Marine Program. The research was supported in part by grants from the Whitehall Foundation and the National Science Foundation (BNS 8512585 ) to J. A. and a Boston University Graduate Fellowship to F.C.

\section{Literature Cited}

Atema, J. 1977. Functional separation of taste and smell in fish and crustacea. Pp. 165-174 in Olfaction and Taste VI, J. Le Magnen and P. MacLeod, eds. Information Retrieval Ltd., London.

Atema, J. 1985. Chemoreception in the sea: adaptations of chemoreceptors and behavior to aquatic stimulus conditions. Soc. Exp. Biol. Symp. 39: 387-423.

Atema, J., P. F. Borroni, B. R. Johnson, R. Voigt, and L. S. Handrich. 1989. Adaptation and mixture interactions in chemoreceptor cells: mechanisms for diversity and contrast enhancement. $\mathrm{Pp} .83-100$ in Perceptions of Complex Smells and Tastes, D. L. Laing, W. Cain, R. McBride, and B. W. Ache, eds. Academic Press, Sydney.

Borroni, P. F., L. S. Handrich, and J. Atema. 1986. The role of narrowly tuned taste cell populations in lobster (Homarus americanus) feeding behavior. Behav. Neurosci. 100: 206-212.

Buck, L., and R. Axel. 1991. A novel multigene family may encode odorant receptors: A molecular basis for odor recognition. Cell 65: 175-188.

Caprio, J., J. Dudek, and J. J. Robinson 11. 1989. Electro-olfactogram and multiunit olfactory receptor responses to binary and trinary mixtures of amino acids in the channel catfish, Ictalurus punctatus. J. Gen. Physiol. 84: 403-422.

Daniel, P. C., and C. D. Derby. 1987. Mixture interaction analysis: a polymodal model for multiple-receptor systems which incorporates the Beidler equation. Chem. Senses 12: 417-423.

Derby, C. D., and J. Atema. 1982. The function of chemo- and mechanoreceptors in lobster (Homarus americanus) feeding behavior. $J$. Exp. Biol. 98: 317-327.

Derby, C. D., P. M. Reilley, and J. Atema. 1984. Chemosensitivity of the lobster Homarus americanus to secondary plant compounds: unused receptor capabilities. J. Chem. Ecol. 10: 879-892.

Derby, C. D., and J. Atema. 1988. Chemoreceptor cells in aquatic invertebrates: peripheral mechanisms of chemical signal processing in decapod crustaceans. Pp. 365-385 in Sensory Biology of Aquatic Animals, J. Atema, R. R. Fay, A. N. Popper, and W. N. Tavolga, eds. Springer-Verlag, New York.
Devine, D., and J. Atema. 1982. Function of chemoreceptor organs in spatial orientation of the lobster, Homarus americanus: differences and overlap. Biol. Bull. 163: 144-153.

Dionne, V. E. 1992. Chemosensory responses in isolated olfactory receptor neurons from Necturus maculosus. J. Gen. Physiol. 99: 415-433.

Gerardo, H. F, R. Voigt, and J. Atema. 1989. Sclf- and cross-adaptation in chemoreceptor cells. Chem. Senses 14: 702. (Abstract)

Govind, C. K., and F. Lang. 1981. Physiological identification and asymmetry of lobster claw closer motoneurons. J. Exp. Biol. 94: 329339.

Ilatt, H. 1986. Responses of bimodal neurons (chemo- and vibrationsensitive) on the walking legs of the crayfish. J. Comp. Physiol. A 159: 611-617.

Hindley, J. P. R. 1975. The detection, location, and recognition of food by juvenile banana prawns, Penaeus merguiensis de Man. Mar. Behav. Physiol. 3: 193-210.

Johnson, B. R., and J. Atema. 1983. Narrow-spectrum chemoreceptor cells in the antennules of the American lobster, Homarus americanus. Neurosci. Lett. 41: 145-150.

Johnson, B. R., R. Voigt, P. F. Borroni, and J. Atema. 1984. Response properties of lobster chemoreceptors: tuning of primary taste neurons in walking legs. J. Comp. Physiol. 155: 593-604.

Johnson, B. R., P. F. Borroni, and J. Atema. 1985. Mixture effects in primary olfactory and gustatory receptor cells from the lobster. Chem. Senses 10: 367-373.

Johnson, B. R., and J. Atema. 1986. Chemical stimulants for a component of feeding behavior in the common Gulf Weed Shrimp, Leander tenuicornis (Say). Biol. Bull. 170: 1-10.

Merrill, C. L. 1992. Reliability and specificity of hydoxy-L-proline sensitive chemoreceptor cells. Ph.D. Thesis, Boston University, Boston, Massachusetts.

Moore, P. A., N. Scholz, and J. Atema. 1991. Chemical orientation of lobsters, Homarus americanus, in turbulent odor plumes. J. Chem. Ecol. 17: 1293-1307.

Mopper, K., and P. Lindroth. 1982. Diel and depth variations in dissolved free amino acids and ammonium in the Baltic Sea determined by shipboard HPLC analysis. Limnol. Oceanogr. 27: 336-347.

Ogawa, H., S. Yamashita, and M. Sato. 1974. Variation in gustatory nerve fiber discharge pattern with change in stimulus concentration and quality. $J$. Neurophysiol. 37: 443-457.

Reeder, P. B., and B. W. Ache. 1980. Chemotaxis in the Florida spiny lobster, Panulirus argus. Animal Behav. 28: 831-839.

Schmidt, M., and W. Gnatzy. 1987. Contact chemoreceptors on the walking legs of the shore crab, Carcinus maenas. In Taste and Olfaction IX, S. D. Roper and J. Atema, eds. Ann. N. Y. Acad. Sci. 510: $589-590$.

Smith, D. V., and J. B. Travers. 1979. A metric for the breadth of tuning of gustatory neurons. Chem. Senses Flav. 4: 215-229.

Steiner, J., and S. Harpaz. 1987. Behavior stereotypes or food acceptance and the rejection of 'bitter' food in the fresh water prawn, Macrobrachitum rosenbergii. Chem. Senses 12: 89-97.

Tierney, A. J., R. Voigt, and J. Atema. 1988. Response properties of chemoreceptors from the medial antennular filament of the lobster Homarus americanus. Biol. Bull. 174: 364-372.

Voigt, R., and J. Atema. 1992. Tuning of chemoreceptor cells of the second antenna of the American lobster (Homarus americanus) with a comparison of four of its other chemoreceptor organs. J. Comp. Physiol. A171: (in press).

Weinstein, A., R. Voigt, and J. Atema. 1990. Spectral tuning of lobster olfactory cells and their response to defined mixtures and natural food extracts. Chem. Senses 15: 651-652. (Abstract) 